\title{
PENTINGNYA PENGETAHUAN PAJAK DAN SOSIALISASI PAJAK KEPADA CALON WAJIB PAJAK MASA DEPAN
}

\author{
The Importance of Tax Knowledge and Tax Socialization \\ to Future Taxpayer Prospectives
}

\author{
Yohanes Mardinata Rusli ${ }^{1)}$ dan Piter Nainggolan ${ }^{2)}$ \\ 1,2) Jurusan Akuntansi Fakultas IImu Sosial dan Humaniora Universitas Bunda Mulia
}

Diterima 22 Juli 2021 / Disetujui 15 September 2021

\begin{abstract}
Taxation is the most important state revenue. This can be seen in the posture of the 2020 and 2021 RAPBN (Drafted State Revenue and Expenditure Budget), where in the 2020 State Budget the state revenue is 2,233.2 trillion and 1,865.7, which is equivalent to $83.53 \%$, which is the target of domestic revenue which is comes from taxation sector revenues. Only $16.47 \%$ of the targeted state revenue comes from non-tax revenues. Therefore, the importance of taxation is introduced and socialized early on by the taxation authority in Indonesia, namely The Directorate General of Taxes, Finance Ministry of the Republic Of Indonesia (DGT, Ministry Of Finance, RI). This is mandatory because there are still many general public as taxpayers who still do not have awareness of the importance of this taxation. From the data in the 2019 Annual Report of the DGT of the Ministry Of Finance of the Republic of Indonesia, It can be seen that the ratio of of taxpayer compliance in Indonesia to compliance in the submission of tax returns (SPT ) Annual Tax in 2019 for Individual Taxpayers (WPOP) the compliance ratio of both employees and non-employees is $73.23 \%$ and $75.93 \%$, this figure is still far from the maximum compliance level of Individual Taxpayers to be achieved by Government. Therefore, real action is needed from the Directorate General of Taxes, Finance Ministry of The Republic Of Indonesia (DGT, Finance Ministry of The Republic Of Indonesia) to carry out tax counseling activities in collaboration with the academic community Which Is included in the strategic planning of the DGT of Finance Ministry of The Republic Of Indonesia in 2019, namely theme Of increasing tax knowledge and skills where the target is future taxpayers are students who are in high school (SMU). This activity has been carried out by the DGT of Finance Ministry of Republic Of Indonesia in collaboration with several educational institutions, both schools and universities, of which in 2019 there were 1,092 prospective taxpayers (Class X-XII SMA). Therefore, Bunda Mulia University as one of the higher education institutions that has a Tax Center and cooperates and is under Guidance of tthe DGT of Finance Ministry of Republic Of Indonesia, in this case the North Jakarta Regional Tax Office, participates in supporting outreach activities carried out by the DGT of Finance Ministry of Republic Of Indonesia by conducting Community Service activities. . This PKM activity was carried out for class XI students at SMK Budi Asih and class XII students at SMK Dharmasava with online through the media google meeting (G-meet) on February 15, 2021, considering that the current COVID-19 pandemic condition in Indonesia and the world makes PKM activities impossible. done face to face. Furthermore, as many as 53 PKM participants who were individuals who attended SMK Budi Asih, participated in this PKM activity. As for after the PKM activity was held, the authors hope that all individuals who attend SMK Budi Asih can better understand the importance of tax knowledge and tax socialization to ensure that these students, who are prospective future taxpayers, can become obedient taxpayers, so that revenue from the taxation sector which is the main state revenue can be met with the target of state revenue.
\end{abstract}

Keywords: Tax Knowledge, Tax Socialization, Taxpayers, Directorate General of Taxes, Ministry of Finance

*Korespondensi Penulis:

E-mail: yrusli@bundamulia.ac.id 


\begin{abstract}
ABSTRAK
Pajak merupakan pendapatan negara yang paling utama. Di dalam postur RAPBN (Rancangan Anggaran Pendapatan dan Belanja Negara) untuk tahun 2020 dan 2021, dimana pada APBN tahun 2020 penerimaan negara sebesar 2.233,2 Triliun dan sebesar 1.865,7 yaitu setara dengan 83,53\% merupakan target pendapatan dalam negeri dimana berasal dari penerimaan sektor perpajakan Hanya 16,47\% target pendapatan negara yang berasal dari non pajak. Karena itu pentingnya perpajakan dikenalkan dan disosialisasikan sejak dini oleh lembaga otoritas perpajakan di Indonesia, yaitu Direktorat Jendral Pajak Kementrian Keuangan Republik Indonesia (DJP Kemenkeu RI) Hal ini wajib dilakukan karena masih banyak masyarakat umum sebagai Wajib pajak yang masih tidak memilki kesadaran akan pentingnya perpajakan ini, Dari data pada Laporan Tahunan DJP Kemenkeu RI tahun 2019 dapat dilihat bahwa rasio kepatuhan Wajaib Pajak di Indonesia terhadap kepatuhan di dalam penyampaian Surat Pemberitahuan (SPT) Pajak Tahunan pada tahun 2019 untuk Wajib Pajak Orang Pribadi (WPOP) ratio kepatuhan Wajib pajaknya baik karyawan ataupun non karyawan sebesar 73,23\% dan 75,93\%, angka ini masih jauh dari tingkat kepatuhan maksimal Wajib Pajak Orang Pribadi yang ingin dicapai oleh Pemerintah. Karena itu diperlukan tindakan nyata dari DJP Kemenkeu RI untuk melakukan kegiatan penyuluhan Perpajakan yang bekerjasama dengan civitas akademik dimana masuk pada perencanaan strategis DJP Kemenkeu RI tahun 2019 yaitu yang bertemakan meningkatkan pengetahuan dan keterampilan perpajakan dimana sasaran nya ada calon wajib pajak masa depan yaitu para siswa dan siswi SMA, SMK dan Sederajat. Kegiatan ini sudah dilakukan oleh DJP Kemenkeu RI yang bekerjasama dengan beberapa lembaga pendidikan baik sekolah maupun perguruan tinggi, yang mana pada tahun 2019 sudah dilakukan sebanyak 1.092 pada calon wajib pajak masa depan (Kelas X-XII SMA). Karena itu Universitas Bunda Mulia sebagai salah satu perguraun tinggi yang memiliki Tax Center dan bekerjasama serta dibawah binaan dari DJP Kemenkeu RI dalam hal ini adalah Kanwil Perpajakan Jakarta Utara turut serta melakukan kegiatan mendukung kegiatan penyuluhan yang dilakukan oleh DJP Kemenkeu RI dengan melakukan kegiatan Pengabdian kepada Masyarakat (PKM). Kegiatan Pengabdian ini dilakukan dan dilaksanakan kepada siswa kelas XI di SMK Budi Asih pada tanggal 15 Februari 2021 dan siswa kelas XII SMK Dharmasavana pada tanggal 06 Januari 2021 secara Online melalui media google meeting (G-meet), mengingat Himbauan dan situasi pandemi Covid 19 di Indonesia dan dunia membuat pengabdian kepada Masyarakat (PKM) Tidak dilakukan secara Tatap Muka Langsung Selanjutnya, sebanyak total 65 peserta PKM yang merupakan para siswa - siswi yang bersekolah di SMK Budi Asih dan SMK Dharmasavana ikut berpartisipasi dalam pelaksanaan Kegiatan PKM. Setelah Penyelenggarakan Kegiatan Pengabdian masyarakat, penulis berharap bahwa para individu - individu (siswa - siswi) yang bersekolah di SMK Budi Asih dan SMK Dharmasavana dapat lebih memahami lagi pentingnya pengetahuan pajak dan sosialisasi pajak guna memastikan bahwa siswa-siswi ini yang merupalan calon Wajib Pajak Masa Depan untuk dapat menjadi Wajib Pajak yang patuh, sehingga penerimaan dari sektor perpajakan yang merupakan pendapatan negara paling utama dapat terpebuhi target penerimaan pendapatan negara.
\end{abstract}

Kata Kunci: Pengetahuan Pajak, Sosialisasi Pajak, Wajib Pajak, Direktorat Jenderal Pajak, Kemenkeu RI .

\section{PENDAHULUAN}

Pemerintah dalam melaksanakan rencana pemerintahan dan menjalankan pembangunan membutuhkan dana yang besar Dana Tersebut berasal dari hasil pengelolaan potensi sumber daya yang dimiliki suatu negara, baik berupa hasil kekayaan sumber daya alam maupun iuran wajib dari masyarakat.

Pajak merupakan salah satu iuran wajib masyarakat atas kegiatan perekonomian yang dilakukannya. Sebagai salah satu bentuk penerimaaan negara, pajak berperan yang banyak dan semakin menjadi andalan untuk kepentingan menjalankan roda pemerintahan (Pembangunan dan sebagainya). . Ada beberapa fungsi Pajak yaitu fungsi budgetair (sumber penerimaan negara) dan fungsi regulerend (mengatur). Dari fungsi ini menunjukkan bahwa pajak memiliki peran penting sebagai alat penerimaan negara. 
Selain itu peranan pajak juga sebagai alat pelaksanaan berbagai kebijakan pemerintah dalam bidang ekonomi maupun sosial (Resmi, 2020). Dalam pemungutannya, pajak tidak hanya bertujuan untuk menjaga dan meningkatkan momentum pertumbuhan ekonomi, namun juga meningkatkan penerimaan negara.

Kebutuhan akan Pembangunan yang selalu mengalami peningkatan dan permasalahan ekonomi negara membuat pemerintah semakin mengupayakan Optimalisasi Penerimaaan Pajak, Tindakan Pemerintah untuk melakukan Optimalisasi pendapatan negara dapat terlihat dari berbagai peraturan, kebijakan maupun surat keputusan yang dikeluarkan oleh pemerintah. Peraturan Perundang-undangan terkait dengan pajak penghasilan dan dasar penghitungan pajak selalu dioptimalkan.

Sistem Perpajakkan Self Assesment System diterapkan di Indonesia dimana wajib pajak mendapatkan hak untuk melaporkan dan membayar sendiri kewajiban pajaknya. Efektivitas pengumpulan pajak memiliki kendala yaitu kepatuhan wajib pajak ( Tax Compliance). Kendala kepatuhan wajib pajak merupakan masalah yang telah ada sejak lama di bidang pajak. Kepatuhan dalam membayar pajak merupakan hal penting menurut undang - undang pajak penghasilan terutama dalam hal penerapan Self Asessment System. Dalam penerapakn sistem ini diperlukan Kejujuran dan kesadaran wajib pajak dari proses penghitungan hingga pelaporan dalam SP Tahunan (Rasulong, 2018).

Sampai batas pelaporan SPT WPOP tanggal 31 Maret 2018, kepatuhan penyampaian laporan tidak mencapai target yaitu sebesar $64,5 \%$ untuk triwulan 1. Hasil menunjukkan dimana beberapa kantor wilayah sudah mencapai target awal namun beberapa kantor belum mencapai target awal. Kepatuhan Penyampaian ini menjadi salah satu poin penting karena digunakan untuk mengukur rasio pajak dan dalam jangka panjang untuk mengukur kemandirian bangsa.
Dalam APBN 2018, poin terpenting adalah target penerimaan negara dari sektor pajak mencapai targetnya , Sektor penerimaan negara ini ditargetkan mencapai Rp 1878,4 Triliun dengan penerimaan yang berasal dari pajak sebesar $\mathrm{Rp}$ 1609,4 Triliun dan penerimaan negara bukan pajak (PNBP) mencapai Rp 267,9 triliun.

Dari Toral Penerimaan Pajak, dari Pajak Penghasilan $(\mathrm{PPh})$ senilai Rp 852,9 Triliun, pajak Bumi dan Bangunan (PBB) Rp17,3 triliun, pajak pertambahan Nilai (PPN) senilai Rp535,3 triliun dan Pajak lainnya senilai $\mathrm{Rp}$ 9,6 Triliun. Untuk bea masuk ditargetkan mencapai Rp 35,7 Triliun, bea cukai Rp 155,4 Triliun, serta bea keluar sebesar Rp 3 Triliun. Target penerimaan pajak tahun 2018 meningkat 9,3\% dibandingkan target 2017 sebesar Rp 1.472,7 triliun, namun akibat realisasi penerimaan pajak yang belum maksimal serta hanya mencapai persentase 91\% maka target penerimaan pajak di tahun 2018 mengalami kenaikan sekitar 20\% lebih dari realisasi 2017. Target Tax Ratio yang hendak dicapai sebesar 11\%-12\%.

Isu Penerimaan Pajak kembali memanas, karena isu tersebut menyangkut kemandirian bangsa dalam pelaksanaan pembangunan. Hutang Pemerintah akan menjadi sorotan dengan tidak tercapainya target penerimaan perpajakan di tahun 2017. Target pemerintah untuk mempercepat pembangunan infrastruktur dalam kerangka mendorong kegiatan perekonomian yang nantinya akan mengatasi kemiskinan, dan kesenjengan di tengah keterbatasan fiskal, menjadi tantangan tersendiri bagi Direktorat Jendral Pajak (DJP). Dengan demikian yang menjadi masalah utama perpajakkan saat ini adalah cara meningkatkan tingkat kepatuhan yang dimiliki wajib pajak di Indonesia . Pengawasan dan Pemeriksaan tidak hanya saat batas waktu pelaporan pajak tahunan saja, 
Namun sepanjang tahun hal tersebut harus dilakukan untuk meningkatkan kepatuhan wajib pajak dan tercapainya target penerimaan pajak. Pada data tahun 2016, menunjukkan sekitar 32 juta wajib pajak terdaftar dimana terdiri dari wajib pajak yang wajib menyerahkan SPT sebanyak 20 juta, tetapi realisasinya menunjukkan hanya 12 juta atau sekitar 65\%. Pada Data tahun 2017 persentase tersebut sudah meningkat menjadi $70 \%$, sedangkan persentase di negara lain berada di $75 \%-80 \%$

Pemerintah semakin mempermudah sistem pelaporan SPT serta melakukan sosialisasi dan himbauan ke seluruh wajib pajak. Peningkatan kesadaran tidak terlepas dari pengetahuan wajib pajak, baik pengetahuan tentang pelaporan pajak maupun fasilitas perpajakan. Saat ini kemudahan terbatas pada penyampaian dan proses, namun substansi masih dianggap sulit. SPT masih dianggap sebagai dokumen yang sulit diisi dengan benar dan lengkap oleh wajib pajak. Meski sosisalisasi pengisian dan tutorial pengisian sudah dilakukan namun wajib pajak memiliki ketergantungan terhadap petugas pajak maupun konsultan pajak karena tidak mau mempelajarinya sendiri.

Untuk mendorong peningkatan kepatuhan pajak, selain dengan iklan, akan lebih baik menggunakan akademisi dalam proses sosialisasinya. Program Tax goes to campus, Pajak Bertutur dan relawan pajak harus terus dijalankan tiap tahunnya. Selain memperluas pengetahuan pajak sejak dini, program ini juga dapat menjadi sarana sosialisasi bagi para wajib pajak dimana nantinya secara langsung maupun tidak langsung akan meningkatkan tingkat kepatuhan pajak

\section{Indentifikasi Masalah}

Target rasio pajak tahun 2019 yang mencapai $16 \%$, sedangkan realisasi pajak tahun 2016 hanya $10,7 \%$. Rendahnya pencapaian tersebut tentu memiliki dampak terhadap perekonomian Indonesia.

melakukan kegiatan penyuluhan Perpajakan yang bekerjasama dengan civitas akademik dimana masuk pada perencanaan strategis
Untuk mengejar rasio pajak, harus dimulai dengan mengoptimalkan tingkat kepatuhan wajib pajak dalam pelaporan SPT. Wajib pajak belum sepenuhnya menggunakan aplikasi - aplikasi Ditjen Pajak yang mempermudah prroses penyampaian SPT. Pelaporan menggunakan sistem elektronik akan mempermudah Ditjen Pajak dalam melakukan administrasi dokumen yang dilaporkan wajib pajak. Banyak wajib pajak yang masih menggunakan pelaporan dengan sistem manual meskipun sudah ada sosialisasi penggunaaan sistem elektronik.

Kepatuhan pelaporan SPT yang tidak mencapai target $100 \%$ mengakibatkan pajak belum menjadi instrumen yang optimal untuk mewujudkan redistribusi pendapatan dan dalam mengurangi kesenjangan ekonomi. Kewajiban perpajakan yang tidak optimal dalam pelaksanaanya dimana tidak semua wajib pajak berpenghasilan di atas PTKP melakukan pelaporan dengan benar.. Hal ini menyebabkan pembangunan yang telah direncanakan menjadi sedikit terhambat

Agar ratio kepatuhan pajak di Indonesia mencapai 100\% maka Direktorat Jenderal Pajak Kemenkeu RI melakukan perencanaan strategis di dalam penyuluhan perpajakan bagi Wajib Pajak Masa Depan yaitu siswasiswi yang duduk di kelas X-XII atau setara sekolah tingkat menengah atas ( SMA) dan sekolah tingkat menengah Kejuruan ( SMK)

Pada data Annual Report DJP Kementrian Keuangan Republik Indonesia tahun 2019 dapat dilihat bahwa rasio kepatuhan Wajaib Pajak di Indonesia terhadap kepatuhan di dalam penyampaian Surat Pemberitahuan (SPT) Pajak Tahunan pada tahun 2019 untuk Wajib Pajak Orang Pribadi (WPOP) ratio kepatuhan Wajib pajaknya baik karyawan ataupun non karyawan sebesar $73,23 \%$ dan $75,93 \%$, angka ini masih jauh dari tingkat kepatuhan maksimal wajib pajak orang Pribadi yang ingin dicapai oleh Pemerintah. Karena itu diperlukan tindakan nyata dari

DJP Kemenkeu RI tahun 2019 yaitu yang bertemakan meningkatkan pengetahuan dan keterampilan perpajakan dimana sasaran nya 
ada calon wajib pajak masa depan yaitu para siswa siswi di SMA, SMK dan sederajat . Kegiatan ini sudah dilakukan oleh DJP Kemenkeu RI bekerjasama dengan beberapa lembaga pendidikan baik sekolah maupun perguruan tinggi, yang mana pada tahun 2019 sudah dilakukan sebanyak 1.092 pada calon wajib pajak masa depan (Kelas X-XII SMA).

\section{Tujuan dan Manfaat PKM}

Berikut Manfaat dan tujuan atas pelaksanaaan Kegiatan Pengabdian Masyarakat ini :

1. Memperkenalkan sejak dini kepada Calon Wajib Pajak Masa Depan akan pentingnya pajak dan untuk apa dana pajak tersebut bagi negara Indonesia yang merupakan pendapatan paling utama yang disusun pada APBN negara Indoensia.

2. Memberikan wawasan tentang pengetahuan perpajakan yang meliputi bagaimana sister perapajakan yang berlaku di Indonesia, Tarif Perpajakan yang berlaku di Indonesia, serta perhitungan perpajakan bagi Wajb Pajak Orang Pribadi.

3. Memberikan kesadaran kepada peserta kegiatan agar memahami pentingnya pengetahuan dan sosialisasi tentang perpajakan

\section{METODE PENELITIAN}

\section{Metode Penyelenggaraan dan Realisasi \\ Kegiatan}

Menimbang situasi dan kondisi saat ini di Indonesia khuisunya di Jakarta dikarenakan himbauan pemerintah atas pandemi COVID 19 dan sesuai ketentuan dari Pemerintah Daerah / Pemprov DKI Jakarta, maka tidak dapat melaksanakan PKM secara tatap muka di lokasi yang telah direncanakan. Atas dasar hal tersebut maka pelaksanaan kegiatan $\mathrm{d}$ PKM ke SMK Budi Asih dan SMK Dharmasava ini dilaksanakan melalui internet dan menggunakan media virtual zoom.

\section{Profil Peserta PKM}

Pelaksanaan Kegiatan Pengabdian Kepada Masyarakat ( PKM ) bertempat di SMK Budi Asih, yang diikuti oleh 65 Peserta PKM yang merupakan individu dan siswa siswi yang bersekolah di SMK Budi Asih dan duduk di bangku kelas XI dan SMK Dharmasava yang duduk di bangku kelas XII. Para peserta kegiatan Pengabdian kepada Masyarakat (PKM) di SMK Budi Asih dan SMK Dharmasava tersebut yang akan menjadi calon Wajib Pajak kelak jika sudah bekerja dan lulus dari bangku sekolah ataupun bangku perkuliahan..

\section{Sesi Pelaksanaan Kegiatan PKM}

Pelaksanaan PKM dilangsungkan dengan waktu sekitar 3 (tiga jam) dimana pelaksanaanya dibagi ke dalam 2 (dua) kali pertemuan untuk masing-masing yaitu siswa kelas XI SMK Budi Asih dan siswa kelas XII SMK Dharmasava, dimana setiap sesi acara dibawakan dan dipresentasikan oleh setiap pemateri (dosen) yang berbeda satu dengan lainnya. Kegiatan ini sendiri dipimpin oleh Bapak Doktor Yohanes Mardinata Rusli, M.Ak, CA., AK dan Bapak Pieter Nainggolan, SE., M.M. Adapun pada setiap sesi presentasi pada kegiatan pengabdian masyarakat.

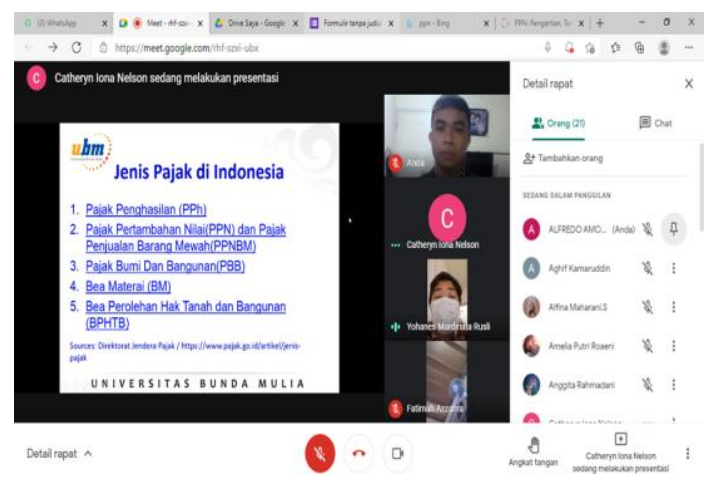

Gambar 1. Penjelasan tentang Jenis-Jenis Pajak di Indonesia

Sumber: Peneliti (2021)

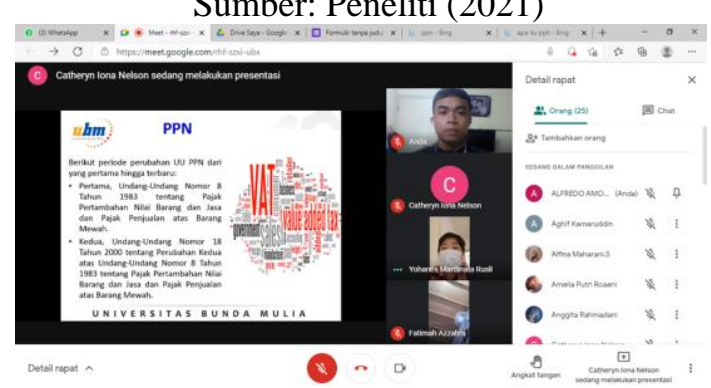

Gambar 2. Penjelasan tentang Pajak Pertambahan Nilai (PPN) Sumber: Peneliti (2021) 
(PKM) pada kali ini membawakan materi tentang kesadaran wajib pajak yang mana membahas tentang pengetahuan perpajakan yang meliputi Pajak Pertambahan Nilai dan Pajak Penjualan atas barang mewah, Pajak Penghasilan Khususnya bagi wajib pajak yang bekerja sebagai karyawan. Setelah sesi pertama telah selesai, pengabdian kepada masyarakat (PKM) ini dilanjutkan dengan sesi pemaparan dan presentasi materi mengenai Sosialisasi perpajakan bagi calon wajib pajak, dimana adalah siswa-siswi SMK itu sendiri yaitu kelas X dan kelas XI.

Pada Kegiatan PKM ini tidak lupa setelah presentasi juga diberikan kesempatan kepada peserta yaitu siswa-siswa kelas $\mathrm{X}$ dan kelas XI SMK Budi Asih untuk bertanya tentang hal-hal perpajakan yang akan menjadi pondasi sebagai wajib pajak yang baik. Terdapat beberapa pertanyaan dari siswasiswi kepada pemateri mengenai pengetahuan perpajakan.

\section{HASIL DAN PEMBAHASAN}

Pelaksanaaan Pengabdian Kepada Masyarakat (PKM) ini dilaksanakan selama 3 (tiga) jam , yaitu jam 09.00-12.00WIB yang diikuti 65 siswa-siswi di dalam 2 (dua) sesi presentasi materi yang berbeda hari untuk kedua sekolah yang dijadikan objek penelitian untuk pengabdian kepada masyarakat dan siswa kelas yang berbeda, yaitu kelas XI SMK Budi Asih dan siswa kelas XII SMK Dharmasava. Kegiatan ini dibagi menjadi 3 (tiga) sesi utama, yang dimana, masing - masing sesi dibawakan dan dipresentasikan oleh setiap dosen ataupun presenter materi topik yang berbeda satu dengan yang lainnya mempresentasikan pengetahuan perpajakan dengan materi Pajak Penghasilan (PPH), Pajak Pertambahan Nilai (PPN) dan PPnBM serta bagi wajib pajak orang pribadi (WPOP).

Kegiatan ini sendiri dipimpin oleh Bapak Dr. Yohanes Mardinata Rusli yang mempresentasikan mengenai Pajak Pertambahan Nilai dan Pajak Penjualan atas Barang Mewah yang diberikan judul: PPN dan PPnBM Beserta Contoh Pencatatan Jurnalnya, yang mana meliputi materi sebagai berikut: (a) Jenis-jenis pajak di Indonesia; (b) Karakteristik PPN dan PPnBM; (c) Pengertian atau Definisi Jurnal Pajak Pertambahaan Nilai (PPN) dan Pajak Pernjulan atas Barang Mewah (PPnBM); (d) Pedoman Penyusunan Jurnal PPN; (e) Perlakuan pencatatan jurnal PPN Keluaran; (f) Perlakuan pencatatan jurnal PPN untuk PPN masukkan.

Pada materi ini diinformasikan pengetahuan dan sosialisasi tentang Pajak Pertambahan Nilai (PPN) dimana pajak ini selalu dikenakan kepada siapa pun yang membeli atau menjual barang. Bagaiaman cara pemungutan pajak nya atas Pajak Pertambahan Nilai (PPN) tersebut dan berapa besar tarif yang berlaku sesuai UU dan peraturan pajak sebagai dasar hukum diberlakukannya PPN tersebut.

Pada sesi presentasi materi selanjutnya untuk Kelas XII SMK Dharmasavana yang dipresentasikan oleh Bapak Piter Nainggolan, SE., M.M. yang memberikan presentasi tentang pengetahuan dan sosialisasi perpajakan dengan materi Pajak Penghasilan $(\mathrm{PPh})$, dimana materi ini disampaikan dengan beberapa poin, yaitu: (a)

Jenis-jenis Pajak Penghasilan; (b) Pajak Penghasilan atas Pasal (PPh Pasal 21) Wajib Pajak orang Pribadi; (c) Pajak Penghasilan Pasal 21 (PPH Pasal 21) Wajib Pajak Badan ./ Perusahaan; (d) PPH 22 (PPh Pasal 22); (e) PPH Pasal 23 (PPh pasal 23). Pada pajak penghasilan dimana diberikan pengetahuan bahwa setiap warga negara Indonesia (WNI) yang sudah berpenghasilan dan diatas umum 17 (tujuhbelas) tahun diwajibkan memiliki nomor pokok wajib pajak (NPWP). Serta ketentuan dan tarif 
perpajakan yang berlaku di Indonesia untuk masing-masing Pajak Penghasilan ( $\mathrm{PPh})$ tersebut. Sebagai Warga Negara yang baik di Indonesia, peserta didik yang nantinya akan berpenghasilan sehingga memiliki kewajiban untuk membayar pajak.

\section{SIMPULAN}

Kegiatan pengabdian masyarakat dengan topik Pajak Pertambahan Nilai dan Pencatatan Jurnalnya dan Pajak Penghasilan dan Pencatatan Jurnalnya secara keselurhan berlangsung dengan lancar dan diskusi aktid dengan para siswa-siswi SMK Budi Asih. Dengan dilaksakannya kegiatan ini diharapkan semua peserta yang berupa siswasioswi SMK Budi Asih menyadari akan kepatuhan wajib pajak dimana pengetahuan perpajakan dan sosialisasi perpajakan yang merupakan hal penting bagi calon wajib pajak dimana mereka nanti akan menjadi WPOP yang patuh terhadap Kewajiban Pajaknya maupun peraturan Undang - undang Perpajakan

Tingkat Pengetahuan Perpajakkan merupakan pemahaman wajib pajak orang pribadi terhadap peraturan dan kebijakan perpajakan sehingga dapat dipahami oleh wajib pajak, Selain itu diharapkan dapat mengerti, mematuhi dan melaksanakan kewajibannya dengan sesuai (Rachmadi \& Zulaikha, 2014). Untuk itu pengetahuan perpajakan yang sejak dini diberikan kepada siswa-siswi sebagai calon wajib pajak sangatlah penting. Hal ini terlihat dari antusias dari peserta webinar pengabdian kepada masyarakat (PKM) yang banyak menanyakan tentang tata cara pembayaran dan pelaporan kewajiban perpajakannya.

Selain itu, sosialisasi perpajakan juga sangat penting diberikan sejak dini juga. Hal ini yang menjadi strategi perencanaan tahunan dari pihak otoritas perpajakan di Indonesia dimana bertindak nyata untuk melakukan kegiatan penyuluhan Perpajakan yang bekerjasama dengan civitas akademik dimana masuk pada perencanaan strategis DJP Kemenkeu RI tahun 2019 yaitu yang bertemakan meningkatkan pengetahuan dan keterampilan perpajakan dimana sasaran nya ada calon wajib pajak masa depan yaitu siswa - siswi di SMA, SMK maupun sederajat. Kegiatan ini sudah dilakukan oleh DJP Kemenkeu RI yang bekerjasama dengan beberapa lembaga pendidikan baik sekolah maupun perguruan tinggi, yang mana pada tahun 2019 sudah dilakukan sebanyak 1.092 pada calon wajib pajak masa depan (Kelas XXII SMA).

Sehingga dapat disimpulkan bahwa pengetahuan perpajakan dan sosialisasi perpajakan sejak dini yang diberikan bagi calon wajib pajak masa depan sangatlah penting dan kegiatan ini harus secara intens dilakukan setiap tahunnya jangan hanya beberapa saat saja, karena harus memiliki kesadaran akan kewajiban perpajakannya perlu ditanamkan kepada calon wajib pajak sejak sedini mungkin sehingga mereka paham mengenai peraturan pajak di Indonesia.

\section{DAFTAR PUSTAKA}

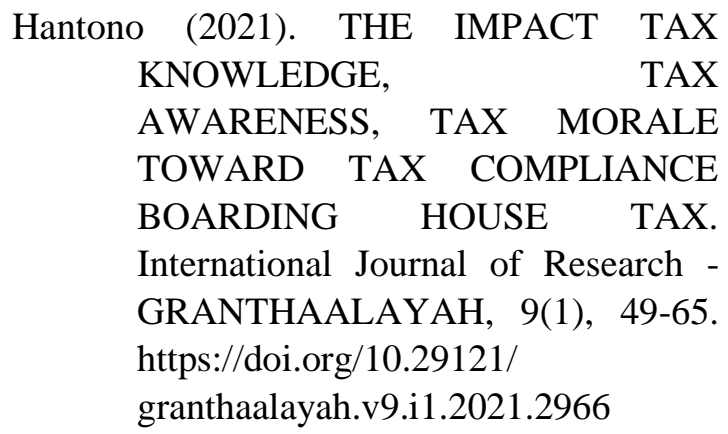

Katuuk, D., Manossoh, H., \& Walandouw, S. K. (2017). Pengaruh Integritas Dan Kreativitas Konsultan Pajak Terhadap Kepatuhan Wajib Pajak. Jurnal Riset Akuntansi Going Concern, 01-08.

Lubis, I., Suryani, S., \& Anggraeni, F. (2018). Pengaruh Kepemilikian Manajerial dan Kebijakan Utang Terhadap Agresivitas Pajak Pada Perusahaan Manufaktur. Jurnal 
Akuntansi dan Keuangan, 7(2), 211226.

Mardiasmo. 2019. Perpajakan Edisi Revisi. Yogyakarta : C.V Andi Offset.

Ni Putu Arisa Dewi “ Pengaruh Kesadaran Wajib Pajak, Pelayanan Fiskus, Dan Sanksi Perpajakan Pada Kemauan Mengikuti Tax Amnesty. E-Jurnal Akuntansi Universitas Udayana. Vol. 19.2, Mei 2017

Paramartha, I Putu Indra. 2016. Pengaruh Kualitas Pelayanan, Pengetahuan Dan Sanksi Perpajakan Pada Kepatuhan Wajib Pajak Badan. Jurnal Akuntansi, 15 (641 - 666). Universitas Udayana.

Resmi, Siti. 2020. Perpajakan Teori dan Kasus. Salemba Empat.

Sugiyono. 2018. Metode Penelitian Administrasi. Cetakan ke-20. Bandung: Alfabeta.

Tim Edukasi Perpajakan Direktorat Jenderal Pajak. (2016). Materi Terbuka Kesadaran Pajak untuk Perguruan Tinggi. Jakarta: Kementerian Keuangan Republik Indonesia Direktorat Jenderal Pajak.

Twum, K. K., Amaniampong, M. K., Assabil, E. N., Adombire, M. A., Edisi, D., Akuetteh, C. (2020). TAX KNOWLEDGE AND TAX COMPLIANCE OF SMALL AND MEDIUM ENTERPRISES IN GHANA. South East Asia Journal of Contemporary Business, Economics and Law, Vol. 21, Issue 5 (April). ISSN 2289-1560.

Zirman. (2015). Pengaruh Penegakan Hukum dan Gender Terhadap Penggelapan Pajak Dimediasi Oleh Moral Pajak. Akuntabilitas, 133-147. 